\title{
Bilateral external ear canal Frey's syndrome: a rare disease
}

\author{
Boon Chin $\mathrm{Te}^{1^{*}}$ (D) and Asma Abdullah ${ }^{1,2}$
}

\begin{abstract}
Background: Frey's syndrome is a socially embarrassing condition commonly involving preauricular area after parotidectomy surgery or trauma to the face. Frey's syndrome over the external ear canal without a prior history of trauma or surgery is extremely rare. To date, there were only two case reports of unilateral spontaneous gustatory sweating in the external ear canal found in the English literature.

Case presentation: We report a case of bilateral external ear spontaneous gustatory sweating in a 31-year-old Chinese male. The diagnosis of Frey's syndrome was confirmed by Minor's Starch lodine test.

Conclusions: Comprehensive history and physical examination are mandatory to reach the diagnosis of Frey's syndrome of external ear canal. The treatment option should be tailored individually.
\end{abstract}

Keywords: Frey's syndrome, Gustatory sweating, External ear canal, Parotidectomy

\section{Background}

Frey's syndrome is not particularly rare. Lucie Frey described the Frey's syndrome in the year 1923 in a 25year-old soldier who had suffered gunshot wounds to the face. Most of the cases have clearly defined precipitating events, such as trauma, which can be a blunt or penetrating injury, surgical intervention, and localized inflammation. It commonly occurs in a patient who had undergone parotidectomy, usually diagnosed within 12 months after the surgery [1]. It is typically occurring over the preauricular region of the face. Ear canal Frey's syndrome is extremely rare, and the diagnosis can be challenging. Only two case reports of unilateral spontaneous gustatory sweating in the external ear canal were reported in the English literature [2,3].

\section{Case presentation}

A 31-year-old Chinese male complained of bilateral watery ear discharge whenever he was having his meal for the past 1 year. It was not associated with activities

\footnotetext{
* Correspondence: boonchin2002@gmail.com

'Department of Otorhinolaryngology, Head \& Neck Surgery, Universiti Kebangsaan Malaysia Medical Centre, 56000, Kuala Lumpur, Malaysia Full list of author information is available at the end of the article
}

involving Valsalva maneuver. Otherwise, he had no known medical illness, such as diabetes mellitus. He had no previous facial surgery, trauma to his ear, or ear canal infection.

There was no scar found over his face, and no cranial nerve abnormality detected. Examination under the microscope revealed that both tympanic membranes were normal and no sinus opening over both the external ear canal. Bilateral external ear canal was not inflamed, and no discharge was seen. Minor's starch iodine test was carried out and showed a positive starch-iodine reaction. In this test, the skin of the external auditory canal was painted with an iodine solution and allowed the solution to dry up (Fig. 1a shows right external ear canal with dried up povidone solution and Fig. 1b shows left external ear canal with dried up povidone solution). The external ear canal skin was then dusted with starch powder (Fig. 2a shows that starch was dusted on the right external ear canal with dried povidone, and Fig. $2 \mathrm{~b}$ shows that starch was dusted on the left external ear canal with dried povidone). The patient was asked to chew a lemon for $2 \mathrm{~min}$ to stimulate saliva production. The presence of sweat in the external auditory canal reacted with the iodine and starch to produce a dark blue color (Fig. 3a shows positive Minor's starch iodine test over right external ear canal
Springer Open

(c) The Author(s). 2020 Open Access This article is licensed under a Creative Commons Attribution 4.0 International License, which permits use, sharing, adaptation, distribution and reproduction in any medium or format, as long as you give appropriate credit to the original author(s) and the source, provide a link to the Creative Commons licence, and indicate if changes were made. The images or other third party material in this article are included in the article's Creative Commons licence, unless indicated otherwise in a credit line to the material. If material is not included in the article's Creative Commons licence and your intended use is not permitted by statutory regulation or exceeds the permitted use, you will need to obtain permission directly from the copyright holder. To view a copy of this licence, visit http://creativecommons.org/licenses/by/4.0/. 


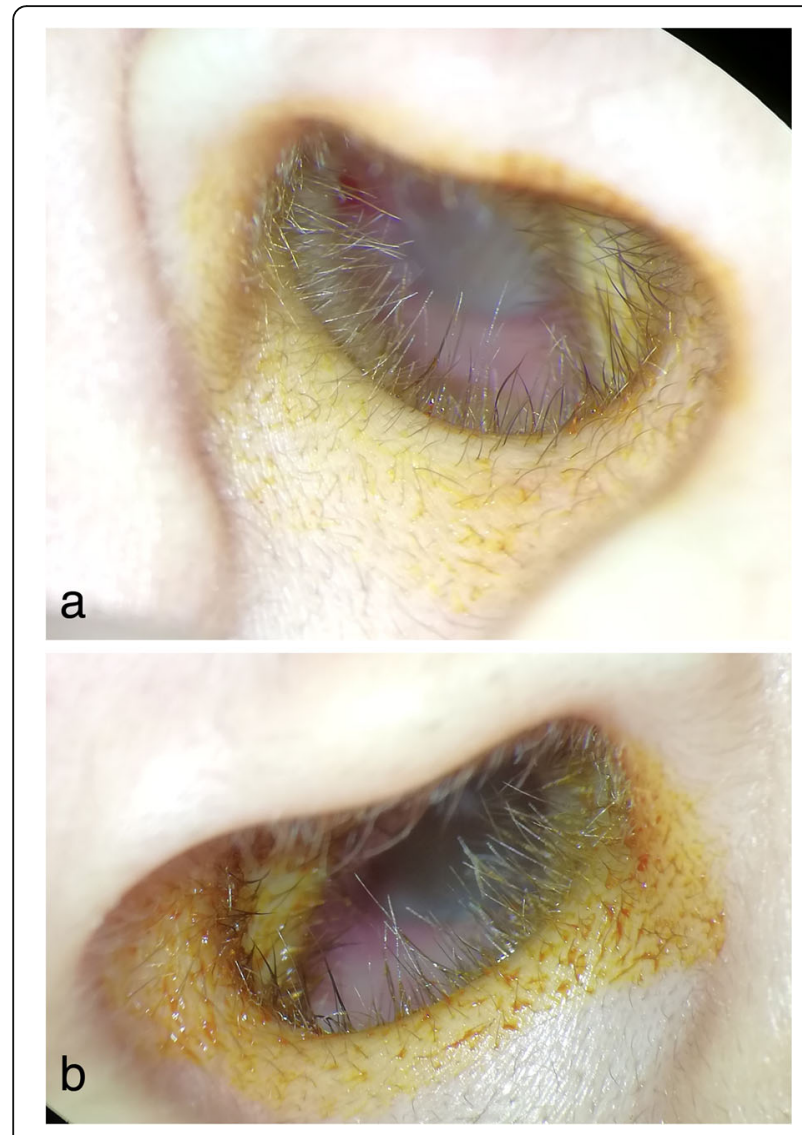

Fig. 1 a Right external ear canal with dried up povidone solution. b Left external ear canal with dried up povidone solution

and Fig. 3b shows positive Minor's starch iodine test over left external ear canal). Diagnosis of Frey's syndrome over bilateral external ear canal was made.

The initial treatment of aluminum trichloro-hexahydrate topical application could only relieve the symptoms temporarily. The symptoms reoccurred if the patient stopped using the medication. For long-term results, he was offered for botulinum toxin injection; however, the patient was not keen on botulinum toxin injection or any other surgical intervention.

\section{Discussion}

Frey's syndrome is believed to be caused by aberrant reinnervation of nerve. These regenerating nerve fibers sometimes fail to find proper distal channels and may penetrate other severed nerve fibers which have different functions. The condition can occur after parotidectomy, submandibular gland excision, mandibular condyle trauma, obstetric trauma by forceps or local infection disturbed the local neuropathway anatomy. As a result, the parasympathetic impulse of salivation causes the sympathetic responses of sweating and vasodilation. Only a few cases found in the literature review had been
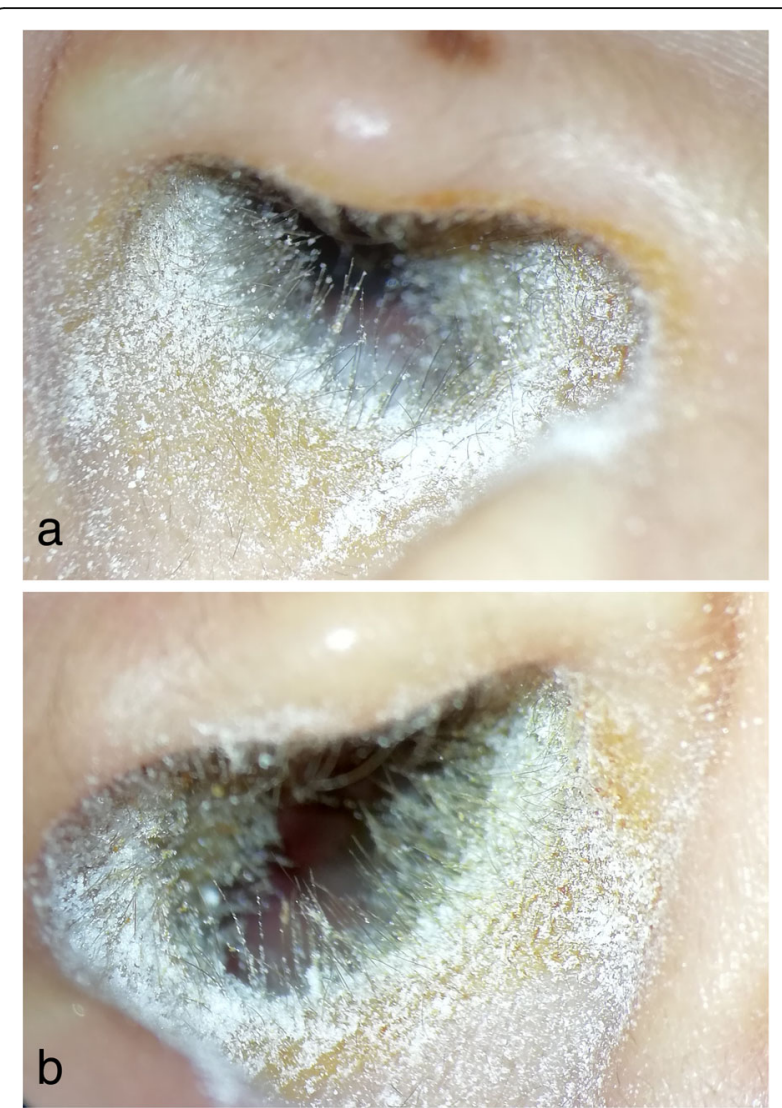

Fig. 2 a Starch was dusted on the right external ear canal with dried povidone. b starch was dusted on the left external ear canal with dried povidone

reported to have gustatory otorrhea, most of them had a prior history of trauma or surgery [4]. It is rare to occur without a previous history of disturbance of normal local anatomy due to surgery or trauma as shown in this case.

Since the intermediate and vagal nerves are adjacent to each other in the middle and external ear, other cross-innervation patterns may occur. Branches of the seventh, ninth, and tenth cranial nerves leave the middle ear to provide sensation and sudomotor innervation to the external auditory canal. While there are parasympathetic fibers to the salivary glands within the middle ear space, the crossover between these sudomotor and parasympathetic fibers is presumably the cause of the Frey's syndrome seen in this patient, although no disruptive incident was found by history or physical examination.

Saito revealed in his dissected temporal bone specimen having clusters of regenerated fibers over the area of the chorda tympani and Arnold's nerves in the tympanic cavity [4]. It had suggested a possibility of mixing and successful bridging of the chorda tympani nerves across a long gap [4]. In the specimen, some fibers are found to wander in various directions to the meatal skin, middle ear mucosa, and tympanic membrane [4]. Thus, it is 

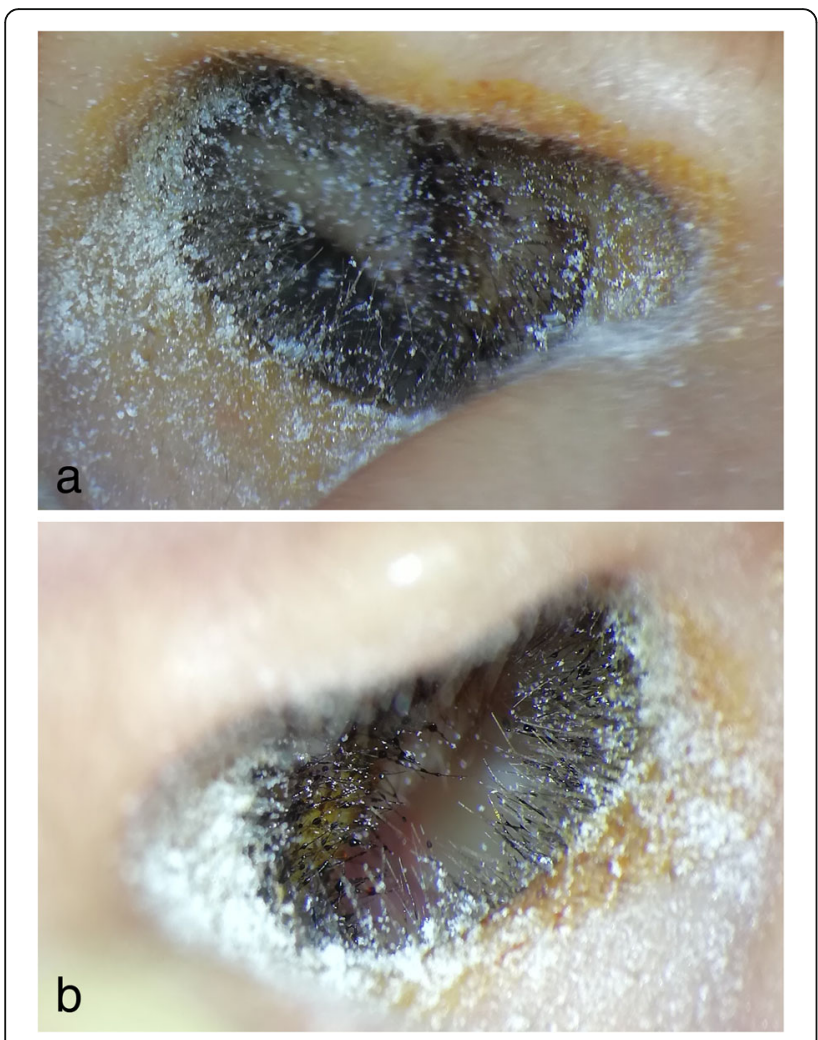

Fig. 3 a Positive Minor's starch iodine test over right external ear canal. b Positive Minor's starch iodine test over left external ear canal

possible cross-innervation syndrome among the nerves innervating the middle and external ear and leading to wet ear syndrome associated with gustatory stimulation of the tongue [4]. However, in our case, there is no significant history of chronic ear disease or ear surgery done before.

In the first reported case of Frey's syndrome involving the external auditory canal, a spontaneous etiology was noted as well [2]. In the case, the skin of the external ear canal was excised as a method of treatment, and subsequent histological examination revealed hypertrophy of the sweat glands. The hypertrophy of sweat glands can be due to the effect of constant stimulation and active production of sweats.

Watery discharge from ear upon eating also raises the suspicion of the presence of fistula from the parotid to the external ear canal. Both structures are anatomically close to each other. A case of a sialocutaneous fistula to external ear canal was reported in a patient with a history of bilateral canaloplasty for congenital auditory canal atresia [5] Fistulation can occur via the fissures of Santorini or occur following trauma to the soft tissue which created the path of least resistance for the saliva flow. In our case, the ear canal skin is intact, and no defects are seen.

The previously reported cases agreed that the treatment protocol should be analogous to the management of Frey's syndrome. Antiperspirants have been used as first-line therapy, but generally, they have a relatively poor outcome. Furthermore, the location deep within the ear canal makes the use of topical agents like antiperspirant and topical anticholinergic medications challenging to access. Topical medication can only relieve the symptoms in the short term, but it has the only few negligible side effects.

Another treatment option is botulinum toxin type A intradermal injection. Botulinum toxin type A is one of the most common subtypes which prevent the release of acetylcholine at nerve terminals and thus blocking neurotransmission. The symptoms of gustatory sweating are under control up to average 6 months after the injection [6]. Some patients can be symptom-free for 20 months after the injection [6,7]. The side effects such as dry mouth, muscular weakness, and painful injection are reported. It takes about 3 months for the side effects to resolve completely [6]. Meanwhile, injection of physiologic saline solution, detaching the skin over the mastoid cavity, had also been used [4]. Botulinum toxin A treatment is minimally invasive, well-tolerated, and longlasting which its effect sustains for more than 6 months, and the treatment can be repeated $[6,8]$.

The surgical options appear to provide the best longterm treatment for those cases refractory to medical treatment. Surgical interventions include the sectioning nerve fibers by elevation of the flap and to interpose barrier tissue such as muscle, temporoparietal fascia, or dermal graft to prevent the regrowth of the nerve to the sweat glands [8]. Redleaf had excised the external ear canal skin in his case and laid a split-thickness skin graft to replace the ear canal skin [2]. It achieved a good outcome, and the patient was completely free of the symptoms. Other than that, tympanic neurectomy can also be used for Frey's syndrome treatment.

\section{Conclusion}

A bilateral external ear canal Frey's syndrome without any predisposing factors is extremely rare. A proper history and comprehensive physical examination will give the diagnosis of Frey's syndrome. The treatment option should be tailored individually as medical treatment carries no significant side effect.

\section{Acknowledgements \\ Not applicable}

\section{Authors' contributions:}

BC Te analyzed and interpreted the patient's data and was the primary author who wrote the manuscripts. A Abdullah had provided revisions to scientific content of the manuscript and grammatical revisions to the manuscript. All authors read and approved the final manuscript.

Funding

None. 
Availability of data and materials

Not applicable.

Ethics approval and consent to participate

Not applicable

\section{Consent for publication}

Written informed consent was obtained from the patient for publication of this case report and accompanying images.

\section{Competing interests}

There is no competing interest in this case report.

\section{Author details}

'Department of Otorhinolaryngology, Head \& Neck Surgery, Universiti Kebangsaan Malaysia Medical Centre, 56000, Kuala Lumpur, Malaysia. ${ }^{2}$ Institute of Ear, Hearing and Speech (Institute-HEARS) Universiti Kebangsaan Malaysia, 56000 Kuala Lumpur, Malaysia.

Received: 14 March 2020 Accepted: 14 May 2020

Published online: 22 July 2020

\section{References}

1. Rustemeyer J, Eufinger H, Bremerich A (2008) The incidence of Frey's syndrome. J. of Cranio-Maxillofacial Surg 36:34-37

2. Redleaf, M. I. \& McCabe, B. F (1993) Gustatory otorrhea: Frey's syndrome of the external auditory canal. Ann. Otol. Rhinol. Laryngol 102:438-440.

3. Sonsale, A., Sharp, J. F. \& Johnson, I. J. M (1999) Gustatory sweating of the external auditory canal. J. Laryngol. Otol 113:1000-1001.

4. Saito H (1999) Gustatory otalgia and wet ear syndrome: a possible crossinnervation after ear surgery. Laryngoscope 109:569-572

5. Van Der Woerd, B. D. \& Macneil, S. D (2017) Sialocutaneous fistula to the external auditory canal repaired with superficial parotidectomy and temporoparietal flap. Medicine (Baltimore) 96:e7038.

6. Xie S, Wang K, Xu T et al (2015) Efficacy and safety of botulinum toxin type A for treatment of Frey's syndrome: evidence from 22 published articles. Cancer Med 4:1639-1650

7. Motz, K. M. \& Kim, Y. J (2017) Auriculotemporal syndrome (Frey Syndrome), Otolaryngol Clin North Am 49:501-509.

8. de Bree, R., Van Der Waal, I. \& Leemans, C. R (2007) Management of Frey syndrome. Head Neck 29:773-778.

\section{Publisher's Note}

Springer Nature remains neutral with regard to jurisdictional claims in published maps and institutional affiliations.

\section{Submit your manuscript to a SpringerOpen ${ }^{\circ}$ journal and benefit from:}

- Convenient online submission

- Rigorous peer review

- Open access: articles freely available online

- High visibility within the field

- Retaining the copyright to your article 